\title{
Contraceptive Use in Ghana: What about Women Empowerment?
}

\author{
Edward Kwabena Ameyaw ${ }^{1 *}$, Francis Appiah1, Catherine Selorm Agbesi², Patience Kannor ${ }^{2}$ \\ ${ }^{1}$ Department of Population and Health, Faculty of Social Sciences, University of Cape Coast, Cape Coast, Ghana \\ ${ }^{2}$ Department of Community Medicine, School of Medical Sciences, University of Cape Coast, Cape Coast, Ghana \\ Email: *edmeyaw19@gmail.com
}

How to cite this paper: Ameyaw, E.K., Appiah, F., Agbesi, C.S. and Kannor, P. (2017) Contraceptive Use in Ghana: What about Women Empowerment? Advances in Sexual Medicine, 7, 44-64.

http://dx.doi.org/10.4236/asm.2017.71004

Received: October 4, 2016

Accepted: January 15, 2017

Published: January 18, 2017

Copyright (c) 2017 by authors and Scientific Research Publishing Inc. This work is licensed under the Creative Commons Attribution International License (CC BY 4.0).

http://creativecommons.org/licenses/by/4.0/ (c) (i) Open Access

\begin{abstract}
Introduction: Although contraceptive usage appears to be increasing in Ghana, 30 and 42 percent of married and unmarried women respectively still have unmet need for family planning services partly due to their inability to exercise their basic rights on fertility issues. Meanwhile, expanding freedom of choice and actions to shape women's life is critical to how women can be autonomous about issues surrounding their fertility. On this premise, this study aimed at investigating empowerment status and usage of contraceptives among women in the reproductive age in Ghana. Methods: The study made use of the 2014 Ghana Demographic and health survey with a sample size of 9396 . The outcome variable was contraceptive use whilst the main independent variable was women empowerment (measured by ability to decide on a woman's own healthcare, large household purchases and visiting family members). Both bivariate and multivariate binary logistic regressions were carried out generating odd ratios to explore the association at $95 \%$ confidence interval. Results: The results indicated that women who were not deciding alone on their own healthcare were less probable to use contraceptives $(\mathrm{OR}=0.92, \mathrm{CI}=0.80-1.07)$ as well as those who were not deciding alone on large household purchases $(\mathrm{OR}=0.96, \mathrm{CI}=0.82$ $1.11)$ and visiting family members $(\mathrm{OR}=0.63, \mathrm{CI}=0.93-1.25)$ at the bivariate level. However, at the multivariate level, higher likelihoods of contraceptive use were found among those who were not deciding alone on health $(\mathrm{OR}=1.26, \mathrm{CI}=1.18$ 1.68), large household purchases $(\mathrm{OR}=1.30, \mathrm{CI}=1.08-1.55)$ and visiting family members $(\mathrm{OR}=1.32, \mathrm{CI}=1.12-1.57)$. Conclusion: This has inspired the need to intensify women empowerment interventions through mass media and all possible avenues in order to enhance reproductive health.
\end{abstract}

\section{Keywords}

Contraceptives, Women Empowerment, Ghana, Decision-Making

\section{Introduction}

The positive effects of using contraceptives are clear. It allows individuals to attain their 
fundamental rights by giving them an option to make informed decisions about timing and number of children to have [1]. Besides, it contributes to the overall aggregate of women's health by reducing maternal mortality as well as controlling infant mortality [1] [2]. Thus, too wide or too closely spaced pregnancies and unplanned pregnancies among younger women in particular give rise to health risks for mothers and infants coupled with higher maternal and neonatal mortality rates. These factors, among others provide health rationale for fertility regulation and family planning, which constitutes an essential element of preventive healthcare [3].

Meanwhile, globally, wide disparities exist among women in developed and developing countries in terms of contraceptive use. For instance, only 33 percent of married or in-union women use contraceptives in Africa, compared to 59 percent and 75 percent among their counterparts in the Oceania and North America respectively [1]. Similarly, the trend of contraceptive use among women in their reproductive age group in Ghana is also not too good. Generally, contraceptive use in Ghana is gradually increasing. For instance, modern contraceptive use has increased from 10 to 22 percent from 1993 to 2014 while demand satisfaction for modern contraceptives has also risen from 18 to 30 percent within the same period [4]. At the same time, approximately, 30 and 42 percent of married and unmarried women respectively still have unmet need for family planning services while total demand for family planning service stands at 87 percent for unmarried sexually active women [4].

This projects that women, especially from developing countries such as Ghana, are still vulnerable manifesting in the abuse of their rights and privileges in the areas of education, health, politics, economics and reproductive issues thereby putting them at a higher risk of deaths and sexually transmitted infections [5]. Accordingly, over the years, implementation of innovative measures and interventions to holistically better the lives of women has been the focus of global communities. Typically, prior to the inception of Sustainable Development Goals (specifically goal 5 which succinctly looks at gender equality and empowerment of females), the Millennium Development Goal 3 was set to promote equality and women empowerment [6].

Similarly, Ghana has implemented several programs and strategies to be at par with global vision of ensuring a quality health for women and children. For instance, the Ghana National Family Planning Programme was initiated in 1970 under the Ministry of Finance and Economic Planning to provide needed services and support to couples and individuals to have the opportunity to freely determine the number and spacing of children they desire [7]. The Maternal and Child Health as well as Ghana National Planning Programme (MCH/FP) were later fused under the Ministry of Health since the health of women and children were still a primary concern of the nation. The country further migrated from $\mathrm{MCH} / \mathrm{FP}$ to a wide scope of services of reproductive health. Again, the healthcare system has been layered in five levels, ranging from health posts, health centres and clinics, district hospitals, regional hospitals and teaching hospitals and people can access family planning and other reproductive issues at each level. All these levels are funded by the government through internally generated fund and donor agencies [8], however, contraceptives are provided at a cost.

What constitutes women empowerment has been defined in several ways. Momsen 
conceptualised women empowerment as a broad development process that enables people to gain self-confidence and self-esteem to allow them to actively participate in development decision-making [9] while Oxfam [10] also viewed woman empowerment as challenging the forms of oppression which compel people to play a part in their society on issues which are inequitable, or in ways that refute their human rights. However, the Human Development Report conceptualised women empowerment as the full involvement of women in every decisions and processes that shape their lives [11]. Building on these definitions, the element of 'decision-making' is central in women empowerment [12]. Therefore, women empowerment in this study shall denote the ability for women to decide on their own healthcare, large purchases and visiting family members.

Women's participation in household decision-making which is a core dimension of women empowerment has been noticed as an influential element to women's wellbeing particularly towards decision-making on contraceptive use [13] [14]. However, over the years, women have been disempowered and therefore under-represented in almost all spheres of life ranging from education, employment to participation in politics and other leadership positions in Ghana. A nationwide report by the Ghana Statistical Service indicated that there were 27 percent of males between 15 to 64 years engaged in all forms of waged employment, as compared only 8.9 percent females [15]. A similar report from the Women in Public Life Project also indicated that majority (95\%) of employees who occupy the lowest rank in the civil services such as secretaries and receptionists were women. Additionally, the data revealed that no woman had occupied a higher rank such as Chief Director and not until 2003 where this situation slightly improved where 2 in 11 chief directors of Ministries in the country were women [16] [17]. However, evidence suggests that there is gradual transformation whereby married women are now being able to participate in decision-making [18].

We must admit that plethora of studies have been conducted to investigate determinants of contraceptive use in Ghana [19] [20] [21] [22] but how empowerment dimension transforms into contraceptive use among women in Ghana is not known. This gap has warranted the need for this current study to explore women's empowerment status and contraceptive usage with the 2014 Demographic and Health Survey (DHS) of Ghana for fertility regulation policy direction and public health importance.

\section{Theoretical Framework}

The study was informed by the Planned Behavioral Theory (PBT) which was adapted as shown in Figure 1. The theory was developed by Ajzen to address the flaws identified in the Theory of Reasoned Action [23]. PBT has attitude, subjective norm and perceived behavioral control as its main constructs which affect intentions and behavior [24]. Since its inception, it has been applied in predicting individual's intentions to engage in safe sex and safe needle [25]. It has also been used extensively to study wide range of human behaviours including predicting individual's dietary intake and intention to use oral contraceptives among Muslims [26] [26] and to predict individuals' intention to use condom and intentions to engage in healthy behaviours [28] [29] [30] [31]. Despite the usefulness of the theory, it has some inherent limitations. For in- 


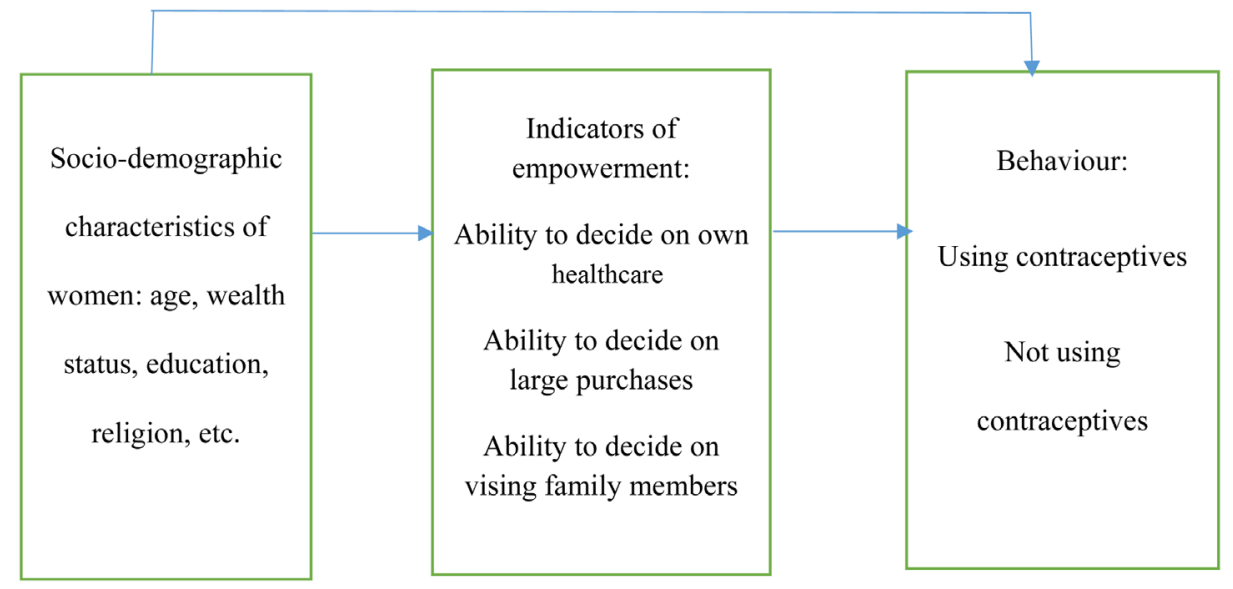

Figure 1. Adapted planned behavoiur theory (Ajzen, 1991).

stance, an attitude (a major construct in the theory) has been found to be weakly correlated to behavior [32] [33].

This theory was however modified because originally it does not recognise empowerment (as measured by decision-making on women healthcare, large household purchases and visiting family members) and socio-demographic characteristics which are anticipated to induce contraceptive use. Therefore, the core constructs of the theory (attitude, subjective norm and perceived behavioural control) are substituted with the three indicators of empowerment and demographic characteristics of women as depicted in Figure 1. In this study, women's ability to use contraceptives is expected to be dependent on their empowerment status. Thus, in the context of this study, women who can take any of the decisions of empowerment alone are expected to utilise contraceptives compared to their counterparts who are not able to decide independently. In the same vein, we also argue that women's socio-demographic characteristics will affect their contraceptive use either directly or indirectly by operating through the three indicators of empowerment and finally influence their contraceptive use as seen in Figure 1.

\section{Methods}

\subsection{Study Setting}

The study setting is Ghana which is centrally located on the West African coast and has a total land area of $238,537 \mathrm{~km}^{2}$. It lies about $750 \mathrm{~km}$ north of the equator between latitudes $4^{\circ}$ North and $12^{\circ}$ North as well as longitudes $4^{\circ}$ West and $2^{\circ}$ East [4]. According to the 2010 Population and Housing Census (PHC), Ghana's population stood at $24,658,823$. The census report revealed that generally, the country's population is very youthful with 58.3 percent being 24 years or less [34].

The Ghana National Family Planning Programme was initiated in 1970 under the Ministry of Finance and Economic Planning on the premise that it constitutes fundamental human right and couples must have the opportunity to freely determine the number and spacing of children they desire [7]. Maternal and Child Health as well as Ghana National Planning Programme (MCH/FP) were later fused under the Ministry of Health. The country migrated from MCH/FP to a wide scope of services of repro- 
ductive health. Both Social Welfare and Ministry of Health contribute immensely toward the interpersonal communications programme and recruitment of new clients for family planning [7].

The healthcare system is composed of five levels: health posts, health centres and clinics, district hospitals, regional hospitals and teaching hospitals. All these levels are funded by the government through internally generated fund and donor agencies [8]. Some health facilities in Ghana are operated by religious bodies (35\%), and are collectively referred to as Christian Health Association of Ghana (CHAG). Generally, health facilities and personnel in the country are unevenly distributed with urban centres having more hospitals, clinics, doctors, nurses and pharmacists [35].

\subsection{Data Source}

The study made use of the women file from the 2014 Ghana Demographic and Health Survey dataset. The Demographic and Health Survey (DHS) collects data on various facets of women wellbeing including issues pertaining to their empowerment status and contraceptive usage. Sample size constituted 9396 women (aged 15 - 49) from 11,835 households in the country. The 2014 GDHS was carried out with an updated frame developed from the 2010 Population and Housing Census. The 2014 GDHS constituted two-stage sample design in order to allow estimates of core indicators at the national level.

The first stage comprised selection of sample points (clusters) involving enumeration areas (EAs) in which 427 clusters consisting of 216 and 211 from urban and rural areas respectively were selected. A systematic sampling of households characterised the second stage in which household inventory operation was conducted within all the identified EAs. Additionally, households to participate in the survey were randomly selected from the list. In order to control for biases arising from either under-reporting or over-reporting, the data was weighted with the weighting factors that were added to the data file.

\subsection{Description of Variables}

The outcome variable was contraceptive usage whereas the independent variable was women empowerment. Within the context of Demographic and Health Survey (DHS), standard indicators for measuring women empowerment comprise four cardinal elements: woman's ability to decide on her own healthcare, ability to decide on large household purchases, ability to decide on household purchases for daily needs and ability to decide on visiting family members. However, no data was captured about decision on household purchases for daily needs by the survey so the remaining three indicators were considered in determining women's empowerment status.

To ensure clarity of results, some variables were recorded. Specifically, marital status was recorded into not married $=0$ and married $=1$, occupation as not working $=0$; primary $=1$; secondary $=2$ and tertiary $=3$, religious affiliation was recorded as Christianity $=1$; Islam $=2$; Traditionalist $=3$ and No Religion $=4$, parity into At most four $=$ 0 ; More than four $=1$ bearing in mind that the current fertility rate of the country stands at 4.1 . 


\subsection{Data Analysis}

In our analysis, since we intended to explore whether the decisions are taken by the women alone or otherwise, all the three indicators were coded into binary. With this, ability to decide was coded as 1 whereas inability to decide independently was coded as zero. The study focused on women who actually used contraceptives within the five year period preceding the survey. We first conducted an exploratory analysis to identify the pattern between women who were empowered or not across their socio-demographic characteristics with the aid of descriptive statistics. Since the outcome variable was binary, we employed binary logistic regression analysis and presented the results in hierarchical order where socio-demographic variables were controlled for after exploring the effects of each of the empowerment indicators on the outcome variable. The results were weighted with the available sample weight factor within the GHDS data in order to reduce sampling biases. All analyses were conducted with STATA version 13.1.

\subsection{Ethical Issues}

With Ghana Statistical Service (GSS), Ghana Health Service (GHS), and National Public Health Reference Laboratory (NPHRL) of the GHS serving as implementing partners and ICF International proving technical support, the 2014 GDHS sought ethical clearance from the Ethical Review Committee of both Ghana Health Service and ICF International. Also free informed consent was sought from the participants during recruitment and administration of the survey instrument [4].

\section{Result}

\subsection{Descriptive Results}

As indicated, women empowerment status was determined by their decision-making ability on their own healthcare, large household purchases and decision on visiting family members. Analysis of decision on a woman's own healthcare in Ghana revealed that most Ghanaian women do not decide on their own healthcare alone $(72.9 \%)$ as indicated in Table 1. This same observation was made when considering decision on large household purchases and decision on visiting family members as 77.6 percent and 73.9 percent respectively were not taking such decisions alone.

The study indicated that most Ghanaian women in the reproductive age group are not empowered (89\%). Since the study targeted women in the reproductive age group, their ages ranged from ranged from 15 to 49 with the mean age of 30 years (SD, 9.7 years). Almost half of the women were rich (46\%) whilst few had attained higher/tertiary education (6.3\%). Christianity was the leading religion $(80.2 \%)$ followed by Islam (15.2\%). Married women (58\%) were more than the unmarried (42\%) as indicated in Table 1. It was further realised that urban residents (53.7\%) exceeded their rural counterparts.

A significant share of the women was engaged in tertiary occupation (45.3\%) which was about two fold of the non-working category (23.7\%). All their partners were working in either primary (35.4\%), secondary (36.3\%) or tertiary $(28.3 \%)$ economic activities. Most women had maximum of four children (72.6\%) whilst 27.4 percent had more than four. 
Table 1. Socio-demographic characteristics of research participants $(\mathrm{N}=9396)$.

\begin{tabular}{|c|c|c|}
\hline Socio-demographic Characteristics & $\mathrm{N}$ & Percent (\%) \\
\hline \multicolumn{3}{|l|}{ Decision on own healthcare } \\
\hline Not Alone & 3921 & 72.9 \\
\hline Respondent Alone & 1460 & 27.1 \\
\hline \multicolumn{3}{|l|}{ Decision on large household purchases } \\
\hline Not Alone & 4176 & 77.6 \\
\hline Respondent Alone & 1205 & 22.4 \\
\hline \multicolumn{3}{|l|}{ Decision on visiting family members } \\
\hline Not Alone & 3977 & 73.9 \\
\hline Respondent Alone & 1403 & 26.1 \\
\hline \multicolumn{3}{|l|}{ Age cohort } \\
\hline $15-19$ & 1625 & 17.3 \\
\hline $20-24$ & 1613 & 17.2 \\
\hline $25-29$ & 1604 & 17.1 \\
\hline $30-34$ & 1372 & 14.6 \\
\hline $35-39$ & 1295 & 13.8 \\
\hline $40-44$ & 1030 & 10.9 \\
\hline $45-49$ & 855 & 9.1 \\
\hline \multicolumn{3}{|l|}{ Wealth Status } \\
\hline Poor & 3148 & 33.5 \\
\hline Middle & 1938 & 20.6 \\
\hline Rich & 4310 & 45.9 \\
\hline \multicolumn{3}{|l|}{ Highest Education level } \\
\hline No education & 1792 & 19.1 \\
\hline Primary/JHS & 1672 & 17.8 \\
\hline Secondary/SHS & 5337 & 56.8 \\
\hline Higher/tertiary & 594 & 6.3 \\
\hline \multicolumn{3}{|l|}{ Religion } \\
\hline Christianity(1) & 7430 & $80.2(1)$ \\
\hline Islam & 1407 & 15.2 \\
\hline Traditionalist & 186 & 2.0 \\
\hline No Religion & 243 & 2.6 \\
\hline \multicolumn{3}{|l|}{ Marital Status } \\
\hline Married & 3932 & 42.4 \\
\hline Not Married & 5337 & 57.6 \\
\hline \multicolumn{3}{|l|}{ Residential Status } \\
\hline Rural & 4346 & 46.3 \\
\hline Urban & 5049 & 53.7 \\
\hline \multicolumn{3}{|l|}{ Occupation } \\
\hline Not working & 2196 & 23.7 \\
\hline Primary & 1729 & 18.7 \\
\hline Secondary & 1140 & 12.3 \\
\hline Tertiary & 4190 & 45.3 \\
\hline \multicolumn{3}{|l|}{ Partner's Occupation } \\
\hline Primary & 2178 & 35.4 \\
\hline Secondary & 2229 & 36.3 \\
\hline Tertiary & 1741 & 28.3 \\
\hline \multicolumn{3}{|l|}{ Parity } \\
\hline At most four & 4641 & 72.6 \\
\hline More than four & 1752 & 27.4 \\
\hline
\end{tabular}




\subsection{Logistic Regression Results on Decision on Own Healthcare and Contraceptive Use}

Two models were constructed in exploring the effect of decision-making on a woman's own healthcare and contraceptive use. Whilst Model I (bivariate) only accounted for relationship between the decision and contraceptive use, Model II (multivariate) further controlled for the effects of some socio-demographic factors. At the bivariate level, it was found that women who were not taking decision on their own healthcare alone were less probable to use contraceptives as compared to those who were taking such decision alone $(\mathrm{OR}=0.92, \mathrm{CI}=0.80$ - 1.07). However, at the multivariate level, women who were not taking healthcare decision alone were more likely to use contraceptives $(\mathrm{OR}=1.26, \mathrm{CI}=1.18-1.68)$ as depicted in Table 2 .

Contraceptive use across age revealed that women in all age categories had higher tendency to utilise contraceptives especially those aged 15-19 $(\mathrm{OR}=27.10, \mathrm{CI}=14.01$ 52.21) whereas those with higher/tertiary education were similarly noted to have higher tendency of contraceptive use than their counterparts without any education (OR = $1.64, \mathrm{CI}=1.03-2.63)$. Women without any religious affiliation were noted to be two times more probable to use contraceptives as compared to Traditionalists $(\mathrm{OR}=2.28$, $\mathrm{CI}=1.35$ - 3.85). Again, tendency for rich Ghanaian women to use contraceptives was noted to be low as compared to poor women $(\mathrm{OR}=0.64, \mathrm{CI}=0.47-0.85)$ whilst at the same time, rural residents were highly inclined toward contraceptive use than their urban counterparts $(\mathrm{OR}=1.29, \mathrm{CI}=1.05-1.58)$.

Table 2. Logistic regression results on decision on own healthcare and contraceptive use.

\begin{tabular}{|c|c|c|}
\hline Independent Variables & $\begin{array}{l}\text { Contraceptives Use } \\
\text { Model I OR (95\% CI) }\end{array}$ & $\begin{array}{c}\text { Contraceptive Use } \\
\text { Model II OR (95\% CI) }\end{array}$ \\
\hline \multicolumn{3}{|l|}{ Decision on own healthcare } \\
\hline Respondent alone & 1.0 & 1.0 \\
\hline Not Alone & $0.92(0.80-1.07)$ & $1.26^{*}(1.18-1.68)$ \\
\hline \multicolumn{3}{|l|}{ Age cohort } \\
\hline $45-49$ & & 1.0 \\
\hline $15-19$ & & $27.10^{\star * *}(14.07-52.21)$ \\
\hline $20-24$ & & $17.17^{\star * *}(11.39-25.91)$ \\
\hline $25-29$ & & $15.92^{\star * *}(10.95-23.15)$ \\
\hline $30-34$ & & $12.14^{\star * *}(8.48-17.39)$ \\
\hline $35-39$ & & $7.09^{* * *}(4.98-10.08)$ \\
\hline $40-44$ & & $3.13^{\star * \star}(2.16-4.52)$ \\
\hline \multicolumn{3}{|l|}{ Highest Education level } \\
\hline No education & & 1.0 \\
\hline Primary/JHS & & $1.20(0.95-1.50)$ \\
\hline Secondary/SHS & & $1.29^{*}(1.03-1.62)$ \\
\hline Higher/tertiary & & $1.64^{*}(1.03-2.63)$ \\
\hline \multicolumn{3}{|l|}{ Religion } \\
\hline Traditionalist & & 1.0 \\
\hline Christianity & & $1.94^{\star *}(1.29-2.90)$ \\
\hline Islam & & $1.44(0.95-2.19)$ \\
\hline No Religion & & $2.28^{\star}(1.35-3.85)$ \\
\hline
\end{tabular}




\section{Continued}

Marital Status

Not Married

Married

$1.04(0.87-1.26)$

Wealth Status

Poor

1.0

Middle

$0.74^{\star}(0.58-0.94)$

Rich

$0.64^{*}(0.47-0.85)$

Residential Status

Urban

1.0

Rural

$1.29(1.05-1.58)$

Occupation

Not working

1.0

Primary

$0.93(0.72$ - 1.19)

Secondary

$1.02(0.77-1.35)$

Tertiary

$0.93(0.74-1.17)$

Partner's Occupation

Tertiary

1.0

Primary

$0.92(0.72-1.17)$

Secondary

$1.16(0.88-1.32)$

Partner's education

No education

1.0

Primary/JHS

$0.85(0.65-1.11)$

Secondary

$0.98(0.77-1.23)$

Higher/tertiary

$0.91(0.64-1.30)$

Parity

At most four

1.0

More than four

$1.61^{\star * *}(1.32-1.97)$

Ecological Zone

Coastal

1.0

Forest

$1.30^{\star *}(1.07-1.57)$

Savanna

$1.59^{\star * *}(1.25-2.03)$

Knowledge on any contraceptive method

Knows no method

Knows only traditional method

$1.84(0.47-7.18)$

Knows only modern method

$2.28(1.00-5.23)$

Knowledge on ovulatory cycle

Don't know

1.0

During period

$1.21(0.81-2.05)$

After period ended

$0.93(0.75-1.26)$

Middle of the cycle

$1.08(0.84-1.42)$

Before period begins

$1.42(1.05-2.05)$

At any time

$0.70(0.49-1.01)$

NHIS Subscription

No

1.0

Yes

$1.38^{\star \star \star}(1.17-1.63)$

Exponentiated coefficients; $95 \%$ confidence intervals in brackets ${ }^{\star} p<0.10 ;{ }^{* *} p<0.05 ;{ }^{* * *} p<0.001$. 
As noted in Table 2, both women in primary ( $\mathrm{OR}=0.93, \mathrm{CI}=0.72-1.19)$ and tertiary occupations $(\mathrm{OR}=0.93, \mathrm{CI}=0.74-1.17)$ had less likelihoods of contraceptive use unlike women in secondary occupation $(\mathrm{OR}=1.02, \mathrm{CI}=0.77-1.35$ ) when compared with those who were not working. Similarly, those whose partners were engaged in primary occupation were noted to have less likelihood of contraceptive use when compared with those whose partners were into tertiary occupation $(\mathrm{OR}=0.92, \mathrm{CI}=0.72$ 1.17). The study revealed that women with more than four children $(\mathrm{OR}=1.61, \mathrm{CI}=$ 1.32 - 1.97) were more probable to use contraceptives than those with at most four children.

It was noted that both women in the Forest zone $(\mathrm{OR}=1.30, \mathrm{CI}=1.07-1.57)$ and Savanna zone $(\mathrm{OR}=1.59, \mathrm{CI}=1.25-2.03)$ had higher tendencies of contraceptive use as compared to women in the Coastal zone. Women who knew only modern method of birth control were twice more probable to use contraceptives as compared to their counterparts who did not know any method ( $\mathrm{OR}=2.28, \mathrm{CI}=1.00-5.23)$. However, analysis of knowledge on ovulatory cycle indicated that women who are able to identify prior to the beginning of their period had higher tendency of contraceptive use as compared to women without any idea about their ovulatory cycle $(\mathrm{OR}=1.42, \mathrm{CI}=1.05$ - 2.05) whilst those subscribed to the National Health Insurance Scheme (NHIS) were also more probable to use contraceptives $(\mathrm{OR}=1.38, \mathrm{CI}=1.17-1.63)$ as compared to their counterparts who had not subscribed.

\subsection{Logistic Regression Results on Decision on Large Household Purchases and Contraceptive Use}

In Table 3, logistic regression results on decision on large household purchases and contraceptive use was presented. As noted in Model I, women who did not take such decision alone were less likely to use contraceptives as compared to those who solely decided on large household purchases $(\mathrm{OR}=0.96, \mathrm{CI}=0.82-1.11)$. However, a counter observation was made in Model II upon controlling for the effects of socio - demographic variables $(\mathrm{OR}=1.30, \mathrm{CI}=1.08-1.55)$.

Across various age groups, all women particularly those aged 15 - 19 were noted to have higher possibility of contraceptive use as compared to those aged 45 - 49 (OR = 26.87, CI $=14.07$ - 52.21) whilst those with higher/tertiary education were also more likely to use contraceptives than uneducated women $(\mathrm{OR}=1.64, \mathrm{CI}=1.03-2.63)$. As compared to Traditionalists, women without any religious affiliation were more inclined toward contraceptive use in Ghana ( $\mathrm{OR}=2.27, \mathrm{CI}=1.34$ - 3.83) whereas married women were relatively more likely to use contraceptives than unmarried women $(\mathrm{OR}=1.05, \mathrm{CI}=0.87-1.26)$.

Table 3. Logistic regression results on decision on large household purchases and contraceptive use.

\begin{tabular}{ccc}
\hline Independent Variables & $\begin{array}{c}\text { Contraceptives Use } \\
\text { Model I OR (95\% CI) }\end{array}$ & $\begin{array}{c}\text { Contraceptive Use } \\
\text { Model II OR (95\% CI) }\end{array}$ \\
\hline $\begin{array}{c}\text { Decision on large household purchases } \\
\text { Respondent alone } \\
\text { Not Alone }\end{array}$ & 1.0 & 1.0 \\
\hline
\end{tabular}




\section{Continued}

Age cohort
$45-49$
$15-19$
$20-24$
$25-29$
$30-34$
$35-39$
$40-44$

Highest Education level

No education

Primary/JHS

Secondary/SHS

Higher/tertiary

Religion

Traditionalist

Christianity

Islam

No Religion

Marital Status

Not Married

Married

Wealth Status

Poor

Middle

Rich

Residential Status

Urban

Rural

Occupation

Not working

Primary

Secondary

Tertiary

Partner's Occupation
1.0

$26.87^{\star * *}(14.07-52.21)$

$17.17^{\star * *}(11.39-25.91)$

$15.95^{\star * \star}(10.96-23.20)$

$12.22^{\star * \star}(8.53-17.51)$

$7.12^{\star * *}(5.00-10.02)$

$3.12^{\star * *}(2.16-4.52)$

1.0

$1.20(0.95-1.50)$

$1.29^{*}(1.03-1.62)$

$1.64^{*}(1.03-2.63)$

1.0

$1.93^{*}(1.29-2.90)$

$1.48(0.97-2.24)$

$2.27^{\star *}(1.34-3.83)$

1.0

$1.05(0.87-1.26)$

1.0

$0.73(0.58-0.93)$

$0.63(0.47-0.84)$

1.0

$1.28^{*}(1.05-1.57)$

1.0

$0.92(0.71-1.19)$

$1.03(0.78-1.36)$

$0.94(0.74-1.18)$

Tertiary

1.0 


\section{Continued}

\begin{tabular}{|c|c|}
\hline Primary & $0.91(0.70-1.18)$ \\
\hline Secondary & $1.16(0.93-1.44)$ \\
\hline \multicolumn{2}{|l|}{ Partner's education } \\
\hline No education & 1.0 \\
\hline Primary/JHS & $0.87(0.66-1.13)$ \\
\hline Secondary & $0.99(0.79-1.25)$ \\
\hline Higher/tertiary & $0.91(0.64-1.30)$ \\
\hline \multicolumn{2}{|l|}{ Parity } \\
\hline At most four & 1.0 \\
\hline More than four & $1.62^{* * *}(1.32-1.97)$ \\
\hline \multicolumn{2}{|l|}{ Ecological Zone } \\
\hline Coastal & 1.0 \\
\hline Forest & $1.32^{* *}(1.07-1.57)$ \\
\hline Savanna & $1.60^{* \star \star}(1.25-2.04)$ \\
\hline \multicolumn{2}{|c|}{ Knowledge on any contraceptive method } \\
\hline Knows no method & 1.0 \\
\hline Knows only traditional method & $1.64(0.42-6.42)$ \\
\hline Knows only modern method & $2.31^{\star}(1.00-5.28)$ \\
\hline \multicolumn{2}{|l|}{ Knowledge on ovulatory cycle } \\
\hline Don't know & 1.0 \\
\hline During period & $1.22(0.81-2.05)$ \\
\hline After period ended & $0.90(0.75-1.26)$ \\
\hline Middle of the cycle & $1.06(0.84-1.42)$ \\
\hline Before period begins & $1.39(0.97-1.99)$ \\
\hline At any time & $0.71(0.50-1.01)$ \\
\hline \multicolumn{2}{|l|}{ NHIS Subscription } \\
\hline No & 1.0 \\
\hline Yes & $1.38^{* * *}(1.17-1.63)$ \\
\hline
\end{tabular}

Exponentiated coefficients; $95 \%$ confidence intervals in brackets ${ }^{*} p<0.10 ;{ }^{* *} p<0.05 ;{ }^{* * *} p<0.001$.

Rural women were more likely to use contraceptives as compared to those in urban settings $(\mathrm{OR}=1.28, \mathrm{CI}=1.05-1.57)$ whilst women engaging in primary $(\mathrm{OR}=0.92$, $\mathrm{CI}$ $=0.71-1.19)$ and tertiary occupations $(\mathrm{OR}=0.94, \mathrm{CI}=0.74-1.18)$ were noted to have less likelihood of contraceptive use than non-working women. It was also observed that those having more than four children were highly inclined toward contraceptive use than women having at most four children $(\mathrm{OR}=1.62, \mathrm{CI}=1.32-1.97)$. Again, women who knew only traditional method $(\mathrm{OR}=1.64, \mathrm{CI}=0.42-6.42)$ or only modern method $(\mathrm{OR}=2.31, \mathrm{CI}=1.00-5.28)$ were more likely to have used contraceptives than those without knowledge about any method. Also, women who had subscribed to the 
NHIS were more probable to use contraceptives $(\mathrm{OR}=1.38, \mathrm{CI}=1.17-1.63)$ than those who had not subscribed.

\subsection{Logistic Regression Results on Visiting Family Members and Contraceptive Use}

Analysis of decision-making on visiting family members and contraceptive use revealed that women who were not deciding alone were less likely to use contraceptives $(\mathrm{OR}=$ $0.63, \mathrm{CI}=0.93-1.25)$ in Model I as indicated in Table 4. However, upon controlling for socio-demographic variables, those who were not deciding alone had higher tendency of contraceptive use as compared to women deciding alone $(\mathrm{OR}=1.32, \mathrm{CI}=1.12$ - 1.57) as indicated in Model II.

The study found that as compared to women aged $45-49$, those in all other age categories had higher tendency to utilise contraceptives particularly 15 - 19 aged women $(\mathrm{OR}=27.08, \mathrm{CI}=14.06-52.18)$. Women with higher/tertiary education were more likely to use contraceptives as compared to their colleagues without education ( $\mathrm{OR}=$ $1.64, \mathrm{CI}=1.03-2.63)$. At the same time, those without religious affiliation were twice more probable to use contraceptives as compared to women affiliated to Traditionalist religion $(\mathrm{OR}=2.27, \mathrm{CI}=1.34-3.83)$ whereas married women also had a relatively high likelihood of contraceptive use over non married women $(\mathrm{OR}=1.05, \mathrm{CI}=0.87-1.26)$.

With regard to wealth quintile, both women in the middle $(\mathrm{OR}=0.73, \mathrm{CI}=0.58$ $0.93)$ and rich wealth categories $(\mathrm{OR}=0.63, \mathrm{CI}=0.47-0.84)$ were less probable to use contraceptives as compared with poor women. Also, rural women were more likely to use contraceptives as compared with the urban folks $(\mathrm{OR}=1.28, \mathrm{CI}=1.05-1.57)$. Whilst women engaging in primary $(\mathrm{OR}=0.94, \mathrm{CI}=0.72-1.20)$ and tertiary occupation ( $\mathrm{OR}=0.94, \mathrm{CI}=0.75-1.18$ ) were less likely to use contraceptive as compared to their non-working counterparts, those working in the secondary sector were more probable to use contraceptives $(\mathrm{OR}=1.03, \mathrm{CI}=0.78-1.37)$.

The study revealed that women whose partners were engaged in secondary occupation were more probable to use contraceptives $(\mathrm{CI}=1.16, \mathrm{OR}=0.93-1.44)$, unlike those whose partners were engaging in primary occupation $(\mathrm{OR}=0.91, \mathrm{CI}=0.70$ 1.18). Again, women whose partners had attained secondary education $(\mathrm{OR}=0.98, \mathrm{CI}$ $=0.79-1.25)$ were less likely to use contraceptives as compared to those whose partners had no formal education. It is worthy of note that women having more than four children were at a greater likelihood of contraceptive use as compared to their counterparts with at most four children $(\mathrm{OR}=1.63, \mathrm{CI}=1.33-1.98)$. On ecological basis, those in the Forest $(\mathrm{OR}=1.34, \mathrm{CI}=1.07-1.57)$ and Savanna $(\mathrm{OR}=1.59, \mathrm{CI}=1.25-2.03)$ zones had higher tendency of contraceptive use than Coastal zone women.

Upon assessing their knowledge about contraceptive methods, both women who knew only traditional method $(\mathrm{OR}=1.58, \mathrm{CI}=0.41-6.16)$ and modern method $(\mathrm{OR}=$ $2.24, \mathrm{CI}=0.98-5.13)$ were at higher tendency of contraceptive use as compared to those who did not know any contraceptive method. On knowledge of ovulatory cycle, when compared with women who do not know, those who get to know either during their period (OR - 1.17, CI $=0.81-2.05)$, middle of the cycle $(\mathrm{OR}=1.05, \mathrm{CI}=0.84$ $1.42)$ or before period begins $(\mathrm{OR}=1.37, \mathrm{CI}=0.96-1.96)$ were more likely to use contraceptives. However, women who knew their cycle anytime $(\mathrm{OR}=0.70, \mathrm{CI}=0.49$ - 
Table 4. Logistic regression results on visiting family members and contraceptive use.

\begin{tabular}{|c|c|c|}
\hline Independent Variables & $\begin{array}{l}\text { Contraceptives Use } \\
\text { Model I OR (95\% CI) }\end{array}$ & $\begin{array}{c}\text { Contraceptive Use } \\
\text { Model II OR (95\% CI) }\end{array}$ \\
\hline \multicolumn{3}{|c|}{ Decision on visiting family members } \\
\hline Respondent alone & 1.0 & 1.0 \\
\hline Not Alone & $0.63(0.93-1.25)$ & $1.32(1.12-1.57)$ \\
\hline \multicolumn{3}{|l|}{ Age cohort } \\
\hline $45-49$ & & 1.0 \\
\hline $15-19$ & & $27.08^{\star * *}(14.06-52.18)$ \\
\hline $20-24$ & & $17.03^{* * *}(11.29-25.68)$ \\
\hline $25-29$ & & $15.74^{\star \star \star}(10.82-22.89)$ \\
\hline $30-34$ & & $12.00^{* * *}(8.40-17.19)$ \\
\hline $35-39$ & & $7.00^{* * *}(4.92-9.95)$ \\
\hline $40-44$ & & $3.09^{\star \star \star}(2.14-4.47)$ \\
\hline \multicolumn{3}{|l|}{ Highest Education level } \\
\hline No education & & 1.0 \\
\hline Primary/JHS & & $1.20(0.95-1.50)$ \\
\hline Secondary/SHS & & $1.29^{*}(1.03-1.62)$ \\
\hline Higher/tertiary & & $1.64^{\star}(1.03-2.63)$ \\
\hline \multicolumn{3}{|l|}{ Religion } \\
\hline Traditionalist & & 1.0 \\
\hline Christianity & & $1.93^{\star \star}(1.29-2.90)$ \\
\hline Islam & & $1.48(0.97-2.24)$ \\
\hline No Religion & & $2.27^{\star \star}(1.34-3.83)$ \\
\hline \multicolumn{3}{|l|}{ Marital Status } \\
\hline Not Married & & 1.0 \\
\hline Married & & $1.05(0.87-1.26)$ \\
\hline \multicolumn{3}{|l|}{ Wealth Status } \\
\hline Poor & & 1.0 \\
\hline Middle & & $0.73^{\star}(0.58-0.93)$ \\
\hline Rich & & $0.63^{\star \star}(0.47-0.84)$ \\
\hline \multicolumn{3}{|l|}{ Residential Status } \\
\hline Urban & & 1.0 \\
\hline Rural & & $1.28^{\star \star}(1.05-1.57)$ \\
\hline Occupation & & \\
\hline
\end{tabular}




\section{Continued}

Not working

Primary

Secondary

Tertiary

Partner's Occupation

Tertiary

Primary

Secondary

Partner's education

No education

Primary/JHS

Secondary

Higher/tertiary

Parity

At most four

More than four

Ecological Zone

Coastal

Forest

Savanna

Knowledge on any contraceptive method

Knows no method

Knows only traditional method

Knows only modern method

Knowledge on ovulatory cycle

Don't know

1.0

During period

$1.17(0.81-2.05)$

After period ended

Middle of the cycle

Before period begins

At any time

NHIS Subscription

No

1.0

Yes

$1.38^{\star * *}(1.17-1.63)$

Exponentiated coefficients; $95 \%$ confidence intervals in brackets ${ }^{*} p<0.10 ;{ }^{* *} p<0.05 ;{ }^{* *} p<0.001$. 
$0.99)$ and those who got to know their cycle at the end of their period $(\mathrm{OR}=0.89, \mathrm{CI}=$ 0.67 - 1.17) were less probable to use contraceptives. Again, those who had subscribed to the NHIS were highly inclined toward contraceptive use $(\mathrm{OR}=1.38, \mathrm{CI}=1.17$ 1.63).

\section{Discussion}

This study investigated how empowerment status (measured by woman's ability to decide on her own healthcare, ability to decide on large household purchases and ability to decide on visitation to family members) affects contraceptive use in Ghana using the sixth round of the Ghana Demographic and Health Survey (2014 GDHS). The study found that women who were not taking decision on their own healthcare alone were less probable to use contraceptives as compared to those who were taking such decision alone. The reason could possibly be that, a woman who is able to decide on her healthcare independently is much particular about the consequences of unplanned and mistimed pregnancies. However, those who are unable to decide alone on their health might be facing suppression which may dissuade them from deciding on timing and type of contraceptive to use. In line with the theoretical framework, it has been evident that women empowerment contributes to high possibility of contraceptive use in Ghana. This is in line with an observation made in India where it was found that women are more likely to use contraceptives when their decision-making competency on their health is not compromised [36].

It was also realised that less likelihood of contraceptive use characterised women who were not deciding on large household purchases alone as compared to those who were deciding alone. Women taking independent decision on large household purchases might probably have control over household resources including income to afford contraceptives, hence, making them more capable to utilise contraceptive with ease. The finding is consistent with the Theory of Planned Behaviour because the use of contraceptive in this context was motivated by the women's ability to decide on large household purchases. The finding is consistent with the Planned Behavior's theoretical proposition that individual's ability to execute the intended behaviour shall be determined by the ability to have control and relative ease to undertake the intended action [23] [24]. The findings is also consistent with the one reported from Tanzania where it was similarly noticed that women who were empowered were more likely to use contraceptives [37].

It was again evident that women who were not deciding alone on visitation to family members were less probable to use contraceptives as compared to those who were deciding alone. This further indicates that, when women are liberated and offered freedom of mobility they will make the right choices regarding their wellbeing particularly regarding issues pertaining to their reproductive health as revealed in this study. Mobility undoubtedly brings about easy flow of information and as such when women are able to move about without coercion they are more probable to interact with other people who might introduce them to the various contraceptives, their relevance and side effects. This finding contradicts an earlier observation that women's sole decisionmaking is not a strong indicator for contraceptive use [38]. However the finding is con- 
sistent with some earlier studies which investigated women empowerment and contraceptive use [38] [39].

The results of the study further indicated that, age of the women was a determinant to contraceptive use and that, women at their youthful stage were more likely to use contraceptives as compared to their other counterparts. Possible explanation to this observation might be that the youth may be highly motivated to use contraceptives as a protective mechanism against unintended pregnancies. However, as one advances in age, individual's desire to have children increases especially in the Ghanaian setting where this is motivated by societal expectations and premium placed on women to give birth. As such women in their late reproductive life are more likely to forego contraceptives in order to bear children. This is in line with the theory of planned behaviour's assertion that individual's behavior is shaped by how their referents expect them to behave. The results also corroborate findings by Nyarko [22] who noticed that, age of adolescents influenced contraceptive usage among female adolescents in Ghana.

Again, the study revealed that educated women were generally more likely to use contraceptives as compared with their colleagues without education. This implies that educated women possibly owing to their knowledge-base in contraceptives are probable to undertake better assessment thereby forming a positive attitude toward contraceptives thereby transforming into higher usage of contraceptives. As argued by the theory of planned behaviour, individuals will engage in any act upon thoughtfully reflecting on the positive outcomes of the intended behavior [23] [24].

Education indirectly also affects contraceptive use on the basis that highly educated women are more likely to engage in highly paid jobs which will subsequently boost their income and enhance their capability to afford contraceptives. The results confirms findings by some earlier studies where they observed that highly educated women were more likely to use contraceptives in Tanzania and Ethiopia [40] [41]. Similarly, it has been observed that women's education influenced their contraceptive usage in Pakistan and Indonesia and that educated women were more likely to use contraceptives than women without education [42] [43].

The study also noticed that women without religious affiliation had a higher chance to use contraceptives. This finding contradicts what was reported by a study using the 2008 GDHS dataset which reported that women affiliated to religious groups were more likely to use contraceptives as compared to their counterparts without any affiliation in Ghana [9]. The observation made in the current study could partly be due to changes in doctrinal teachings that might have taken place over a given period of time and consequently impacted societal expectations and perceptions about contraceptives use. When doctrinal teachings despise the use of contraceptives, it would create negative perception about contraceptives in society, hence, rendering women less motivated to use contraceptive to avoid stigmatisation and discrimination. The underlying assumption of the theory of planned behaviour also strengthens this argument. As explained by the theory, people put up behaviour after realising that, significant others including husbands and relatives favour the intended behaviour [23] [24].

The study also noted that married women were highly probable to use contraceptive than non-married women. In addition to the likelihood of obtaining financial support 
from husbands to secure contraceptives, it is possible that sexual activity is high within marital unions in Ghana, hence accounting for the high contraceptive usage among married women as compared to the non-married women. This is also consistent with some earlier findings from Ghana and Ethiopia [20] [41].

Again, the study noticed that women with higher wealth status were less likely to use contraceptives as compared to low wealth status. It was least expected for women with lower wealth status to use contraceptive more than women with higher wealth status since poor women are unlikely to afford contraceptives as compared to the rich women. A possible explanation to this could arise from the fact that poor women usually noted for high fertility rate are increasingly becoming aware of the need to reduce the number of birth [42]. This result contradict another Ghanaian based study where after exploring the correlates of contraceptive use among women of reproductive age noticed that one's wealth status was positively inclined towards contraceptive use in Ghana [20].

The study also noted that rural women were more probable to use contraceptives, compared with urban dwellers. Possible explanation to this could be as a result of husband approval of smaller family size among rural women. As argued by the theory of planned behaviour, women are more comfortable using contraceptives after realising that their referents (husbands) are in support of and approve [23].

Moreover, the study observed that women working in the secondary sector were more likely to use contraceptives compared with their counterparts in other sectors. As Ajzen purported, individuals embark on any action based on rational choice and that individuals assess the outcome of the intended behavior prior to commencement of that action. Therefore women working in the secondary sector, possibly due to fear of losing their jobs due to pregnancy would rationally choose to use contraceptives in order to secure their jobs.

\section{Conclusion}

The theory of planned behaviour was useful for the study in that the empowerment status (measured by ability to decide independently on one's own healthcare, large household purchases and visiting family members) and socio-demographic characteristics of the women featured in women's contraceptive usage. This study has added knowledge to the existing literature on determinants of contraceptive use in Ghana and has drawn attention to the fact that if women could be empowered, they will be more inclined toward effective use of contraceptive which will in tend aid in controlling fertility and sexually transmitted infections. There is therefore the need to intensify women empowerment interventions through mass media and all possible avenues in order to enhance their reproductive health. Again, the study noted that education influenced contraceptive usage which calls for the need to promote female education in Ghana. Poor women were more likely to use contraceptives which is least expected and this calls for a longitudinal study into the phenomenon.

\section{Limitation of the Study}

The cross sectional nature of the survey does not allow to identity cause and effect. However, the results present a true reflection of the relationship between women em- 
powerment and contraceptive use and thereby provide insights into holistic interventions worth instituting to enhance contraceptive usage in Ghana.

\section{Authors Contribution}

EKA conceived the study, FA and EKA conducted the analysis and interpretation of results, PA and CSA drafted and proof read the manuscript for important intellectual content.

\section{References}

[1] Population Division, Department of Economic and Social Affairs, United Nations (2015) Trends in Contraceptive Use Worldwide 2015 (ST/ESA/SER.A/349).

[2] Rutstein, S. and Winter, R. (2015) Contraception Needed to Avoid High-Fertility-Risk Births, and Maternal and Child Deaths That Would Be Averted. DHS Analytical Studies No. 50, ICF International, Rockville.

[3] Hogue, N. (2007) Trends in the Determinants of the Choice of a Contraceptive Method in Ghana, 1988-2003. American Sociology Association, New York.

[4] Ghana Health Service, Ghana Statistical Service and ICF International (2015) Ghana Demographic and Health Survey 2014. GSS, GHS, and ICF International, Rockville.

[5] Malhotra, A., Schuler, S.R. and Boender, C. (2002) Measuring Women's Empowerment as a Variable in International Development. The World Bank, Washington DC.

[6] United Nations and Republic of Ghana (2015) Ghana Millennium Development Goals 2015 Report. United Nations and Ghana.

[7] Odoi-Agyarko, H. (2003) Profile of Reproductive Health Situation in Ghana. WHO, Geneva.

[8] WHO (2014) The Country Cooperation Strategy. WHO, Geneva.

[9] Momsen, J.H. (2004) Gender and Development. Routledge, London.

[10] Oxfam (1995) The Oxfam Handbook of Relief and Development. Oxfam, Oxford.

[11] UNDP (1998) Human Development Report. Oxford University Press, New York.

[12] Kabeer, N. (2005) Gender Equality and Women's Empowerment: A Critical Analysis of the Third Millennium Development Goal. Gender and Development, 13, 13-24. https://doi.org/10.1080/13552070512331332273

[13] Hameed, W., Azmat, S.K., Ali, M., Sheikh, M.I., Abbas, G., et al. (2014) Women's Empowerment and Contraceptive Use: The Role of Independent versus Couples' Decision-Making, from a Lower Middle Income Country Perspective. PLoS ONE, 9, e104633. https://doi.org/10.1371/journal.pone.0104633

[14] Kishor, S. and Johnson, K. (2005) Women at the Nexus of Poverty and Violence: How Unique Is Their Disadvantage? In: Kishor, S., Ed., A Focus on Gender. Collected Papers on Gender Using DHS Data, ORC Macro, Calverton, 147-180.

[15] Ghana Statistical Service (2008) Ghana Living Standards Survey 5'. Ghana Statistical Service, Accra.

[16] Awumbila, M (2000) Women and Gender Equality in Ghana: A Situational Analysis. In: Tsikata, D., Ed., Gender Training in Ghana: Politics, Issues and Tools, Woeli Publishing Services, Accra.

[17] Ministry of Women and Children's Affairs (MOWAC) (2004) Ghana's Second Progress Report on the Implementation of the African and Beijing Platform of Action and Review Report for Beijing+10. MOWAC, Accra. 
[18] Ghana Statistical Service (GSS), Ghana Health Service (GHS) and ICF Macro (2009) Ghana Demographic and Health Survey 2008. GSS, GHS and ICF Macro, Accra.

[19] Blunch, N.H. (2008) Human Capital, Religion and Contraceptive Use in Ghana. Paper Presented at the Annual Meeting of the Association for the Study of Religion, Economics, and Culture, Lee University, Lexington.

[20] Nketiah-Amponsah, E., Arthur E. and Abuosi, A. (2013) Correlates of Contraceptive Use among Ghanaian Women of Reproductive Age (15 - 49 Years). African Journal of Reproductive Health, 16, 154-166.

[21] Adjei, D., Sarfo, J.O. and Asiedu, M. (2014) Predictors of Contraceptive Use in Ghana: Role of Religion, Region of Residence, Ethnicity and Education. Journal of Advocacy, Research and Education, 1, 3-7.

[22] Nyarko, S.H. (2015) Prevalence and Correlates of Contraceptive Use among Female Adolescents in Ghana. BMC Women's Health, 15, 60.

https://doi.org/10.1186/s12905-015-0221-2

[23] Fishbein, M. and Ajzen, I. (2010) Predicting and Changing Behaviour: The Reasoned Action Approach. Psychology Press, New York.

[24] Ajzen, I. (1991) The Theory of Planned Behaviour. Organisational Behaviour and Human Decision Processes, 50, 179-211.

[25] Bryan, A., Ruiz, M.S. and O’Neill, D.O. (2003) HIV-Related Behaviors among Prison Inmates: A Theory of Planned Behavior Analysis. Journal of Applied Social Psychology, 33, 2565-2586. https://doi.org/10.1111/j.1559-1816.2003.tb02781.x

[26] Povey, R., Conner, M., Sparks, P., et al. (2000) Application of the Theory of Planned Behavior to Two Dietary Behaviors: Roles of Perceived Control and Self-Efficacy. British Journal of Health Psychology, 5, 121-139. https://doi.org/10.1348/135910700168810

[27] Kridli, S.A.O. and Libbus, K. (2002) Establishing Reliability and Validity of an Instrument Measuring Jordanian Muslim Women's Contraceptive Beliefs. Healthcare for Women International, 23, 870-881. https://doi.org/10.1080/07399330290112371

[28] Reinecke, J., Schmidt, P. and Ajzen, I. (1996) Application of the Theory of Planned Behavior to Adolescents' Condom Use: A Panel Study. Journal of Applied Social Psychology, 26, 749-772. https://doi.org/10.1111/j.1559-1816.1996.tb01128.x

[29] Godin, G. and Kok, G. (1996) The Theory of Planned Behavior: A Review of Applications to Health Related Behaviors. American Journal of Health Promotion, 11, 87-98.

[30] Armitage, C.J. and Conner, M. (2001) Efficacy of the Theory of Planned Behaviour: A Meta-Analytic Review. British Journal of Social Psychology, 40, 471-499. https://doi.org/10.1348/014466601164939

[31] Peyman, N. and Oakley, D. (2009) Effective Contraceptive Use: An Exploration of TheoryBased Influences. Health Education Research, 24, 575-585. https://doi.org/10.1093/her/cyn058

[32] Bechtel, R. and Churchman, A. (2002) Handbook of Environmental Psychology. John Wiley, New York.

[33] Winter, D.D. and Koger, S.M. (2004) The Psychology of Environmental Problems. Lawrence Erlbaum, Hillside.

[34] Ghana Statistical Service (GSS) and UNDP (2013) 2010 Population \& Housing Census Report. Millennium Development Goals in Ghana, Accra.

[35] Dixon, J., Tenkorang, E.Y., Luginaah, I.N., Kuuire, V.Z. and Boateng, G.O. (2014) National Health Insurance Scheme Enrolment and Antenatal Care among Women in Ghana: Is There Any Relationship? Tropical Medicine \& International Health, 19, 98-106. https://doi.org/10.1111/tmi.12223 
[36] Patrikar, S.R., Basannar, D.R. and Sharma, M.S. (2014) Women Empowerment and Use of Contraception. Medical Journal Armed Forces India, 70, 253-256. https://doi.org/10.1016/j.mjafi.2013.12.014

[37] Kidayi, P.L., Msuya, S., Todd, J., Mtuya, C.C., Mtuy, T. and Mahande, M.J. (2015) Determinants of Modern Contraceptive Use among Women of Reproductive Age in Tanzania: Evidence from Tanzania Demographic and Health Survey Data. Advances in Sexual Medicine, 5, 43-52. https://doi.org/10.4236/asm.2015.53006

[38] Laili, I., Ilene, S.S. and Jean-Christophe, F. (2014) Relationship Characteristics and Contraceptive Use among Couples in Urban Kenya. International Perspectives on Sexual and Reproductive Health, 40, 11-20. https://doi.org/10.1363/4001114

[39] OlaOlorun, F.M. and Hindin, M.J. (2014) Having a Say Matters: Influence of DecisionMaking Power on Contraceptive Use among Nigerian Women Ages 35 - 49 Years. PLoS ONE, 9, e98702. https://doi.org/10.1371/journal.pone.0098702

[40] Michael, E.J. (2012) Use of Contraceptives Methods among Women in Stable Marital Relations Attending Health Facilities in Kahama District, Shinyanga Region, Tanzania. A Dissertation Submitted in Partial Fulfillment of the Requirements for the Degree of Master of Public Health of Muhimbili University of Health and Allied Sciences, 8-30.

[41] Nigatu, D.T. and Segni, M.T. (2016) Barriers to Contraceptive Use among Child Bearing Women in Ambo Town, West Shewa Zone, Oromia Regional State, Ethiopia, Gynecology \& Obstetrics, 6, 2-5.

[42] Khan, R.E. and Khan, T. (2007) How a Married Woman's Characteristics Affect Her Contraceptive Behavior? Journal of Applied Sciences, 7, 2782-2787. https://doi.org/10.3923/jas.2007.2782.2787

[43] Rahayu, R., Utomo, I. and McDonald, P. (2009) Contraceptive Use Pattern among Married Women in Indonesia. International Conference on Family Planning. Research and Best Practices, Kampala, 15-18 November 2009.

\section{Submit or recommend next manuscript to SCIRP and we will provide best service for you:}

Accepting pre-submission inquiries through Email, Facebook, LinkedIn, Twitter, etc.

A wide selection of journals (inclusive of 9 subjects, more than 200 journals)

Providing 24-hour high-quality service

User-friendly online submission system

Fair and swift peer-review system

Efficient typesetting and proofreading procedure

Display of the result of downloads and visits, as well as the number of cited articles

Maximum dissemination of your research work

Submit your manuscript at: http://papersubmission.scirp.org/

Or contact asm@scirp.org 